\title{
Anhydrous Cooling Mode Applied in External cooling Equipment of HVDC Converter
}

\author{
WEN Yu-liang ${ }^{1, *}$, WANG Guang-wu ${ }^{1}$, LU Zhi-min ${ }^{1}$, CHEN Jian-ye ${ }^{2}$ \\ 1. Guangzhou Goaland Energy Conservation, Tech. Co. Ltd Canton, Guangzhou, 510663 \\ China; \\ 2. Department of Electrical Engineering, Tsinghua University, Beijing 100084, China; \\ *E-mail: wenyl@goaland.com.cn (corresponding author)
}

\begin{abstract}
Anhydrous Cooling Mode is that it consumes little water in the operation process. This paper made some investigates in the external cooling equipment which is currently applied in the HVDC converter substation. There are some anhydrous cooling modes in the HVDC converter substation. A case of anhydrous cooling mode which air cooler series with the water chiller applied in the long distance natural gas pipeline pressurization was introduced. It is recommended that the cooling system composed of air cooler in series with chilling water will be preferentially chosen as an anhydrous cooling mode applied in the HVDC converter external cooling equipment.
\end{abstract}

Keywords: HVDC Thyristor valve; external heat exchanger; Anhydrous Cooling Mode

\section{Introduction}

Anhydrous Cooling Mode is that it consumes little water in the cooling process. As is known, converter valve is the key set of HVDC grid system. Cooling system is an important part of the HVDC converter unit; it plays an important role to the HVDC substation [1]. It is accepted that deionized water is a very efficient cooling medium in the internal circuit of the HVDC converter [2]. There are mainly two types of external cooling sets, one is the air cooler in which the heat transfers from the deionized water to the air outside, the other is the closed circuit cooling towers in which the heat transfer from the deionized water to the water outside which the water will evapour to the air.

Experience from the operation and maintenance, due to the biological corrosion and chemical corrosion, closed circuit cooling tower as the external heat exchanger has much more failure than inner cooling system [3]. There were some failures in such as the spray water pumps, so it was in the risk of been submerged and forced to stop running in rainstorm days, and the spray water pumps and fans for the cooling tower may lose AC power etc.[4]. In addition, the closed circuit cooling towers use too much water, so itis not suitable for the arid sand area. What's more, the effectiveness of the air cooler is based on the temperature difference between the water temperature of the inlet converter and the ambient temperature [5]. Therefore, it is of great significance to research the anhydrous cooling mode of the HVDC converter valve cooling system.

\section{Priciple of Converter Valve Heat Transfer}

The main heat of converter valve was produced by the thyristors, the snubber circuit resistors, and the valve reactors. Then the heat was transferred through the heat sink to the closed-type circuit cooling sytem and to the external heat exchanger, and was let off to the air in the end. The external heat exchanger is the terminal of the deionized water closed-type circuit cooling sytem of the HVDC thyristor valve. The principle of the heat transfer of this external heat exchanger is expressed as the equation below:

$$
Q=k S \Delta T_{m}=k S\left(T_{m}-T_{a}\right)
$$

In the formula, $Q$ is the total heat exchange in heat exchanger and equal to the power losses; $\mathrm{k}$ is the heat exchanger coefficient of heat transfer; $S$ is the surface area of heat exchanger; and $\Delta T_{m}$ is the logarithmic mean temperature difference between the ambient $T_{a}$ and the mean temperature in exchanger $T_{m}$. It will lead to a fluctuation on the output water temperature when the ambient temperature changes.

\section{The external heat exchanger used in tranditional HVDC substation}


There are two types of external heat exchangers, one is closed circuit cooling towers and the other is air cooler, and each is used in different atmasphere. There is also hybrid cooling system to assistant this two type's heat exchanger.

\subsection{Closed circuit cooling towers}

Closed circuit cooling towers belong to wet cooling, they are widely applicable to water rich area. The heat load to be rejected is transferred from the deionized water to the ambient air through a heat exchange coil. There are several substations applied with closed circuit cooling towers such in the substation of China Southern Power Grid as Figure 1.

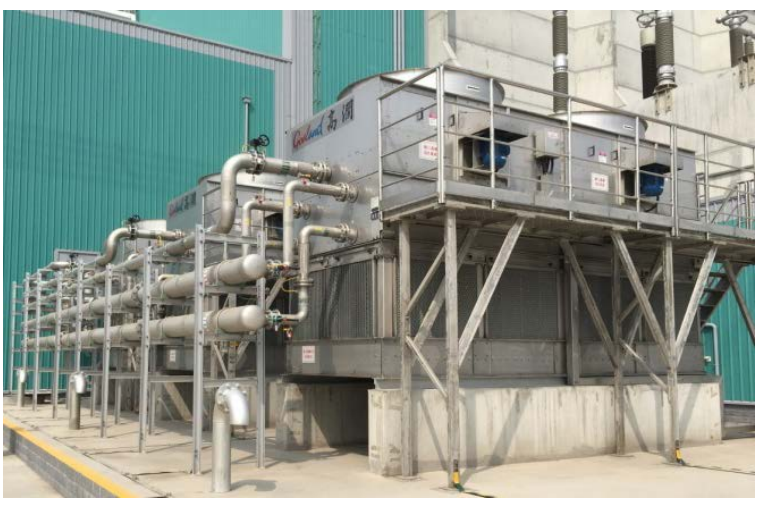

Figure 1. HVDC converter valve substation applied with closed circuit cooling towers

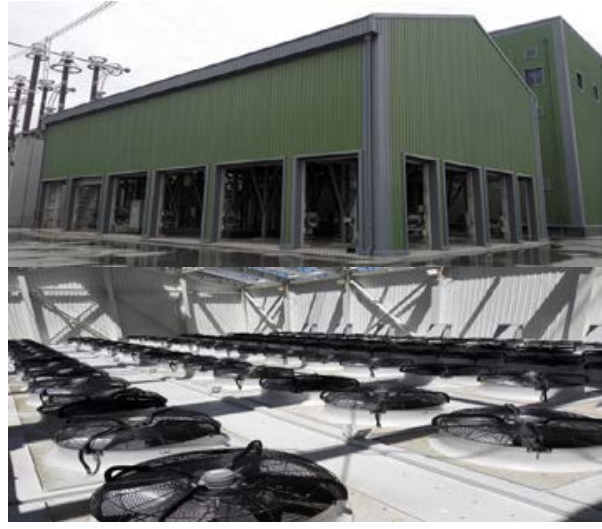

Figure 2. HVDC converter valve substation applied with air cooler

\subsection{Air cooler and air cooler with assistant spraying system}

Air coolers belong to dry cooling is a traditional anhydrous cooling mode. They are cold tolerance, are widely applicable to in the world. Air cooler products consist of a bundle of finned tubes, fabricated most often with "Hifin" tubing which offers a combination of ruggedness and thermal efficiency.There are several substations applied with air cooler and almost all of these substations lie in north China.

The air cooler with an assistant spraying system, as another combination of heat transfer mode, was also introduced to substation and the paper made some reseach in Yinchuan Eastern Converter Substation as Figure 3 [6].

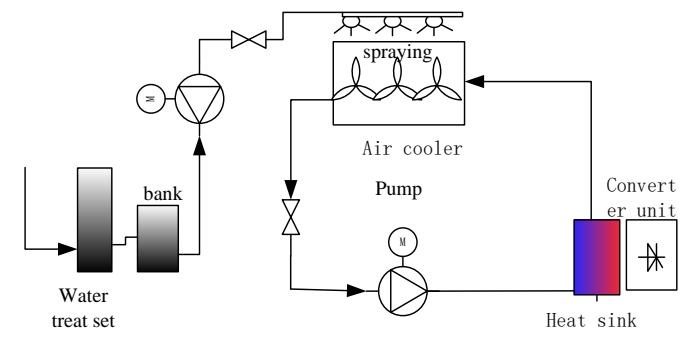

Figure 3. Air cooler with the assistant spraying system

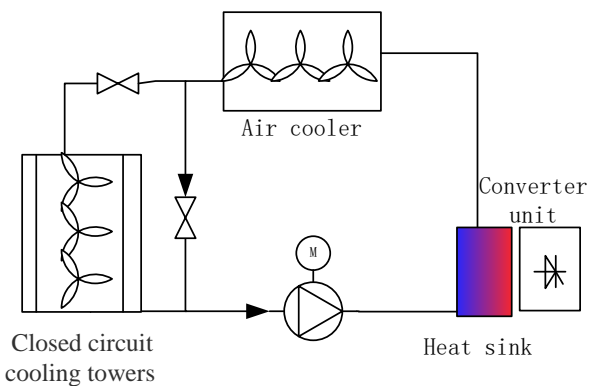

Figure 4. Air cooler in series with closed circuit cooling towers

\subsection{Hybrid cooling mode air cooler series with closed circuit cooling towers}

With the development of HVDC, the hybrid cooling modes were introduced to and applied in the converter cooling system. Cooling system composed of air cooler in series with closed circuit cooling towers was built in the South Hanmi substation as Figure 4. There are advantages of hybrid cooling: lower energy consumption, simplicity in operation and maintenance and experienced in field application. With the operation and maintenance of the South Hanmi substation, another substation also applied the same combination mode, and both of these places are suitable to anhydrous cooling mode.

\subsection{Hybrid cooling mode air cooler with air-cooled chiller}

Refrigeration and air condition systems, which are a mature industry, have become an integral part in the design of spaces occupied by people and intended to provide controlled thermal, humidity, cleanliness, and 
other process requirements[7]. There is no precedent of the air cooler assitant with water chiller in cooling HVDC coverter, but the the water chiller is used in HVDC coverter hall. There are two types of water chiller assitant to the HVDC coverter. Both types combination also need water and water treat set. There is another combination of heat transfer mode of anhydrous cooling, in which chiller maybe is introduced to HVDC substation.

A cooling system with an air-cooled chillers unit in series with air cooler is proposed. Air cooler combinating with the air-cooled chillers provide multiple cooling redundancies as cooling equipment, including: cooling capacity redundancy, and cold source redundancy, which will be more reliability in cooling system as Figure 5.

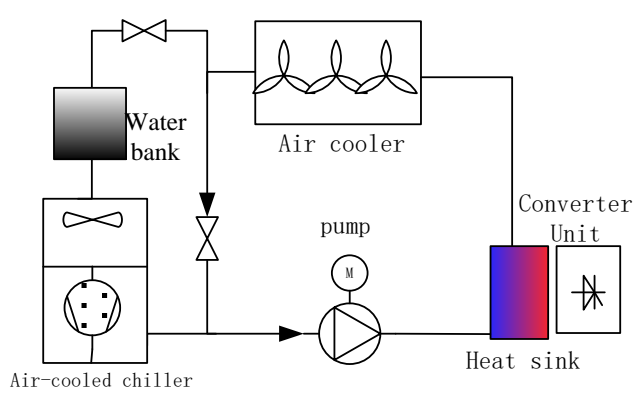

Figure 5. Principle of air cooler series with the air-cooled chiller system

Chilled water storage system series with air cooler is a supplement to the air cooler series with vapor-compressed refrigerator. There will be a large water saver bank in the process. The air-cooled chiller composes a compressor, expansion valve, air condenser and evaporator. It can offer chilled water at ambient of up to $45^{\circ} \mathrm{C}$, especially it can operate at night cooling to save the chilled water in the water saver during the night and prepare for the continuous use in the next daytime, so that HVDC convertor can pass through the extreme environmental high temperature in a stable manner.

\subsection{Comparation of different cooling modes}

From the different cooling modes as upside, we made a table as Tab.1, and each type has its advantage.

Table 1.Comparation of different cooling modes

\begin{tabular}{|c|c|c|c|c|}
\hline project & $\begin{array}{l}\text { Closed circuit } \\
\text { cooling towers }\end{array}$ & $\begin{array}{lr}\text { air cooler or air } \\
\text { cooler } \\
\text { assistant } \\
\text { system }\end{array}$ & \begin{tabular}{lr}
\multicolumn{2}{|c}{ air cooler seried } \\
with Closed \\
circuit cooling \\
towers
\end{tabular} & $\begin{array}{l}\text { Hybrid cooling mode air } \\
\text { cooler with air-cooled } \\
\text { chiller }\end{array}$ \\
\hline area & small & large & middle & middle \\
\hline Water pollution & Water & no & little & no \\
\hline $\begin{array}{l}\text { ambient } \\
\text { temperature } \\
\text { limit }\end{array}$ & Lew point, & $\begin{array}{l}\text { High ambient } \\
\text { temperature }\end{array}$ & no & no \\
\hline Maintenance & $\begin{array}{l}\text { need to remove } \\
\text { scale regularly, or } \\
\text { water treatment } \\
\text { equipment }\end{array}$ & Motor maintenance & $\begin{array}{l}\text { need to remove } \\
\text { scale regularly, } \\
\text { or } \quad \text { water } \\
\text { treatment } \\
\text { equipment }\end{array}$ & $\begin{array}{l}\text { Motor and } \\
\text { maintenance }\end{array}$ \\
\hline Opration cost & more & Middle & Middle & middle \\
\hline Case substation & large & large & Some & no \\
\hline Initial cost & 1 & 1.7 & 2.3 & 2.5 \\
\hline Water cost & $\geq 65$ Million $\mathrm{kg}$ & little & 3 Million kg & 0 \\
\hline
\end{tabular}

\section{Anhydrous Cooling Mode design in with vapor-compress refrigerator}

As well known, the heat exchange efficiency of air cooler decreases with the raise of air temperature, so does the air cooler water chiller. 
The function of air temperature changed with air temperature can be set as $\mathrm{T}=\mathrm{T}(\mathrm{y})$, and $\mathrm{y}$ is the time every hour, so a mathematical model of cooling can be stated as below: Power of cooling equal the Power of air cooler and the Power of air-cooling chiller and the Power of Saver. Because both of the air cooler and the air-cooling chiller are the function of air temperature, so it can express the heat load of HVDC convertor valve as below[8].

$$
Q_{\text {all }}=\int F(T(y)) d y+\int Q(T(y)) d y+P
$$

$Q_{\text {all }}$ is the heat load;

$F$ is the heat function for the Power of air cooler;

$Q$ is the heat for the Power of air-cooling chiller;

$P$ is the power of the coolant storage.

We got the data of the TMY (typical meteorological year), and found the data of $y$ with the max air temperature. The $F$ can be caculated, and it is linear with air temperature. Generally, the condensing temperature is higher than the ambient temperature of $15^{\circ} \mathrm{C}$, that is, $T=15+T_{\mathrm{a}}$, so the $Q$ can be caculated and it is also linear with air temperature. If we get the $Q_{a l l}$, we will set the operating strategy of the HVDC convertor valve.

\section{Case of Appllied of Anhydrous Cooling Mode in inverter cooling}

The frequency conversion motor drive compressor group is applied in the long distance natural gas pipeline pressurization as Figure 6. When the temperature is higher than the design temperature of air cooler, air cooler chillers can be used as an auxiliary cooling device to decrease the cold load of air-cooler in summer.

\section{Conclusions}

This paper analyzes the heat exchanger used in the HVDC thrysitor valve, and studied the external cooling equipment with anhydrous cooling mode. A combined strategy of cooling system with air-cooler chillers and storage acting as auxiliary equipment to the air cooler of HVDC of thrystor was provided. A case of air cooler series with vapor-compressed refrigerator applied in the long distance natural gas pipeline pressurization was introduced. Thus it is recommended that the cooling system composed of air cooler in series with chilling water would be preferentially chosen as the outside cooling system as an anhydrous cooling Mode applied in HVDC converter external cooling equipment.

\section{Acknowledge}

The authors may acknowledge the Canton government for the supply of science fund, fund No. 201802010013, No. 201802010022.

\section{References}

[1] Guo, J., Wang, H., Ai, C.etc. The application of evaporative cooling technology in HDVC converter station[C]. Electrical Machines and Systems (ICEMS), 2013 International Conference on. 2013:2267-2270.

[2] Guide for Test Procedures for HVDC Thyristor Valves[S]. IEEE Std 857-1990. 1990:0_1..

[3] YANG Guang-liang. TAI Neng-ling, ZHENG Xiao-dong. Anyalysis of potential dangers leading to HVDC outage in valve cooling system[J]. Power System Protection and Control. 2010, (18):199-203.

[4] Fang, S., Luo, W., Wang, H. etc. Operational performance of the valve cooling system in Guangzhou converter station[C]. AC and DC Power Transmission, 11th IET International Conference on. 2015:1-5.

[5] Wen, Y., Hu, J., Keyte, J. etc. Water storage for HVDC thyristor valves cooling system topic. [C]. Power Electronics and Applications (EPE'15 ECCE-Europe), 2015:1-5.

[6] ZHANG Bin, WEI Peng. Design and application of auxiliary spraying system in Yinchuan Eastern Converter Station[J]. Ningxia Electric Power 2014, (04):5-9.

[7] Kandlikar, S. G. A Roadmap for Implementing Minichannels in Refrigeration and Air-Conditioning Systems-Current Status and Future Directions[J]. Heat Transfer Engineering. 2007, 28(12):973 — 985.

[8] Wen, Y., Leng, M., Zhang, E. etc. (2014). Hybrid cooling system for HVDC Convertor valves[C]. International Conference on Machinery, Electronics and Control Simulation (ICMECS), L. Wang, ed., 588-595. 